\title{
ANNOTATIONS
}

\section{State Recognition for Sight-Testing Opticians}

The organs of the optical trade having had time by now to read and digest the report of the Council of British Ophthalmologists, together with the annotations contained in some of the leading medical journals, have returned to the charge in full force. The Dioptric Bulletin for August, 1922, gives extracts from the final report of the Departmental Committee on the Causes and Prevention of Blindness (Ministry of Health), as well as excerpts from the report issued to the general Press by the Council of British Ophthalmologists, together with the historical appendix; there is also an editorial in which occurs the statement that " the Committee (Ministry of Health) with its witnesses was composed almost entirely of ophthalmic surgeons and medical men, and that the sprinkling of laymen was almost infinitesimal. Although the two leading societies offered to give evidence, their offer was not taken advantage of, the result being that a purely ex parte statement was drawn up by this Committee, giving the opinion that medical men only were competent to test sight and that opticians as such were incompetent."

The Editor of the Dioptric Bulletin holds that it is necessary for the Committee of the British Optical Association appointed by the Council to consider the question, to act quickly, and in order to stimulate such action, prizes of $£ 10$, $£ 5$, and $£ 1$ are offered for the three best replies to the final report of the Departmental Committee. The Editor deems it unnecessary at the present time to make any reply to "that of the British Medical Journal or to the Council of British Ophthalmologists, which can be dealt with in their own proper turn." These prizes are open to all and sundry, and our readers will be gratified to learn that they can, if they desire, compete for them.

The same journal in its last issue for 1922 prints a letter in answer to the " recent attacks of the Council of British Ophthalmologists, asking why the ordinary medical practitioners consult qualified opticians, and send their wives and families, and also their patients to them "; the writer complains of the illegible writing of ophthalmic surgeons, and of the fact that they do not adopt a standard notation for axes of cylinders; " abundant cases could be brought forward of ametropes being sent by opticians to ophthalmic surgeons for medical treatment and only getting the refraction corrected." "It is ridiculous to suggest that a knowledge of, say, the earlier symptoms of scarlet fever is necessary to correct a case of hypermetropic astigmatism, and it is decidedly 
unfair to lead anyone to believe that qualified opticians treat eye diseases, or that they give the public the impression that they are fully qualified medical practitioners." This letter ends with a bombastic paragraph castigating the Council of British Ophthalmologists as obstructionists, "preventing the qualified optician from becoming a better man." A short letter follows this, in which the writer asks the Association to try and make its members adopt a more professional attitude, and advocating that the advertisement "sight tested free " be forbidden.

The Optician and Scientific Instrument Maker has a leading article on the same lines as the Dioptric Bulletin.

We are entirely unable to follow the organs of the optical trade in this matter; we fail to see why State recognition should make the opticians better workmen than they are. If, on the other hand, the opticians think that the possession of a State diploma will enable them to charge their clients for their advice, as well as for the spectacles, why cannot they be honest and say so ?

We would remind them that in each case of refraction, there is a personal element as well as an optical element; that glasses are made for the patient and not the patient for the glasses, and that it is absurd to treat a human being as if he or she was a mere optical instrument. We believe that the Council of British Ophthalmologists was entirely actuated, in their considered report, by a sense of - public duty, in a matter which has a very distinct bearing on the public health, and we do not see that the two leading societies have any right of grievance at not being called upon to give evidence before the Departmental Committee, which was appointed to consider the causes and prevention of blindness, neither of which subjects, it seems to us, come within the purview of the optical trade.

Should the optical trade succeed in obtaining State recognition, it is obvious that a very large number of their clients will assume that the optician is competent to advise, not only what glasses should be worn, but also in all matters connected with the eye. We have never accused the opticians of treating ophthalmic diseases, but we may remind them that good sight is perfectly compatible with the presence of such serious conditions as chronic glaucoma and optic neuritis, the first of which diseases accounts for a fair percentage of blindness in middle-aged and elderly people; with conditions as they are at present, the optician who is brought into the Law Courts by a patient, who has gone blind while wearing his glasses, has a strong position. He will be the first in such a case to affirm that he is here to sell a pair of glasses and not to advise about diseases of the eye, and the Judge and jury would probably take the common-sense view that 
the patient, under these circumstances, has only himself to blame for his lamentable condition. Will it not be otherwise, if the trade succeed in obtaining their charter?

\section{Medical Students and Ophthalmology}

It is little wonder that the vexed question of what the medical student should be taught of ophthalmology has aroused interest far from these shores. The Archives of Ophthalmology recently printed a weighty paper by Dr. Gordon M. Byers, of Montreal, giving his views upon the subject. Post-graduate instruction does not offer the same difficulties as pre-graduate instruction, mainly, perhaps, because it falls mainly to teachers in the specialities for solution, while under-graduate studies in any one subject are but a single factcr in a much larger problem, in which workers in all branches of medicine are interested. Nobody may at this day hope to master all medical knowledge during his studentship, whatever may have been the case once. The foremost place must be assigned to disorders that involve the issues of life and death, and then to those that lead to complete and permanent disablement. Lastly, come the disorders which are neither menacing nor rare, but of importance since they are common. Judged from this utilitarian standpoint how many eye problems fall into these several groups? Among the major questions are intraocular tumours, malignant growths on and about the eye, wounds and injuries of the orbit, orbital cellulitis, and osteitis from extension or metastasis; the student should be able to distinguish between the various disorders of which proptosis is the most striking sign. Diseases that are danger signals include optic neuritis, choked disc, retinitis or choroiditis, palsies of the muscles of the eve, and visual disturbances expressive of disease in the optic tract. - Disorders that threaten disablement include purulent ophthalmia, trachoma, diphtheria of the conjunctiva, wounds, injuries and burns of the eye. There is demanded a fair knowledge of refraction, ophthalmoscopy, and perimetry in the functional examination of the eye. Byers appears to think that by a re-arrangement of the present curriculum and by the introduction of more effective methods of teaching and study, room could be made for the necessary amount of ophthalmology, which could be given in four months' whole time work, provided the student had had a year of active work in general surgery. Finally, he raises a strong plea for the continued retention of ophthalmology in the general curriculum of medicine. It is clearly impossible that a man could intelligently practise in any special field without a knowledge of medicine and surgery as a whole. 